\title{
O CURRÍCULO E 0 ENSINO RELIGIOSO NA BNCC: REFLEXÕES E PERSPECTIVAS
}

\author{
THE CURRICULUM AND RELIGIOUS EDUCATION AT BNCC: \\ REFLECTIONS AND PERSPECTIVES
EL CURRÍCULO Y LA EDUCACIÓN RELIGIOSA EN LA BNCC: REFLEXIONES Y PERSPECTIVAS

\begin{abstract}
RESUMO: O Ensino Religioso (ER) nos remete a um tema polêmico e vem despertando o interesse de grupos religiosos e educadores da área. O ERé uma das disciplinas mais antigas no currículo escolar no país. No Brasil, não existe oficialmente uma diretriz nacional comum para esta disciplina, capaz de produzir uma ação pedagógica autônoma e reflexiva, que respeite o pluralismo religioso, a diversidade cultural e étnica de seu povo. O objetivo deste artigo é analisar os desafios e as perspectivas do ER como área de conhecimento na Base Nacional Comum Curricular - BNCC, bem como discutir como tal disciplina pode ser uma ação pedagógica dialógica, reflexiva, crítica e emancipadora?
\end{abstract}

Palavras-chave: Currículo. Ensino Religioso. Base Curricular.

ABSTRACT: Religious Education (RE) refers us to a controversial theme and has aroused the interest of religious groups and educators in the area. The ER is one of the oldest disciplines in the school curriculum in the country. In Brazil, there is no official common national guideline for this discipline, capable of producing an autonomous and reflexive pedagogical action that respects religious pluralism, the cultural and ethnic diversity of its people. The objective of this article is to analyze the challenges and perspectives of RE as a field of knowledge in the National Curricular Common Base - BNCC, as well as to discuss how such discipline can be a pedagogical action dialogic, reflexive, critical and emancipating?

Keywords: Curriculum. Religious education. Curricular Base.

RESUMEN: La Enseñanza Religiosa (ER) nos remite a un tema polémico y viene despertando el interés de grupos religiosos y educadores del área. El ER es una de las disciplinas más antiguas en el currículo escolar en el país. En Brasil, no existe oficialmente una directriz nacional común para esta disciplina, capaz de producir una acción pedagógica autónoma y reflexiva, que respete el pluralismo religioso, la diversidad cultural y étnica de su pueblo. El objetivo de este artículo es analizar los desafíos y las perspectivas del ER como área de conocimiento en la Base Nacional Común Curricular - BNCC, así como discutir cómo tal disciplina puede ser una acción pedagógica dialógica, reflexiva, crítica y emancipadora?

Palabras clave: Currículo. Educación religiosa. Base Curricular. 


\section{INTRODUÇÃO}

O Ensino Religioso (ER) no sistema escolar brasileiro nos remete a um tema polêmico e que vem despertando o interesse de grupos religiosos e educadores da área. O ER é uma das disciplinas mais antigas no currículo escolar do país. Apesar disso, o Estado nunca conseguiu implementar uma diretriz nacional curricular para esta disciplina.O que assistimos ao longo da história foi uma ação pedagógica de doutrinação religiosa com forte viés de igrejas hegemônicas, com destaque para a igreja católica. A educação ficou refém de grupos religiosos, que difundiam no espaço escolar suas crenças e ideologias.

Hoje percebemos três modelos de ensino religioso: o catequético, o teológico e o das Ciências da Religião. Enquanto o primeiro revela conteúdos e métodos doutrinários com o objetivo de expansão de crenças, o segundo apresenta uma perspectiva de cosmovisão e diálogo com as diferentes manifestações religiosas, mas ainda com objetivo de educação moral e de formação religiosa do cidadão. O último, no entanto, como tentaremos mostrar neste trabalho, busca os elementos epistemológicos e metodológicos para um ensino de ruptura com o viés doutrinário e monocultural.

No Brasil, como já afirmamos, não existe oficialmente uma diretriz nacional comum capaz de produzir uma ação pedagógica autônoma e reflexiva, que respeite a diversidade cultural, étnica e religiosa. Surgiu, todavia, no Estado de Santa Catarina, em 1996, um movimento de educadores para construir uma nova concepção de Ensino Religioso. Surgia neste Estado o Fórum Nacional Permanente do En-

1 A BNCC está no Plano Nacional de Educação através da Lei 13.005 de 25 de junho de 2014. Podemos observar, no entanto, que a BNCC já aparecia na Constituição Federal do Brasil de 1988, no seu artigo 210 e na Lei de Diretrizes e Bases da Educação Brasileira, LDB, no 9.394/1996. Diz o artigo 210:"Serão fixados conteúdos mínimos para o ensino fundamental, de maneira a assegurar formação básica comum e respeito aos valores culturais e artísticos nacionais e regionais". (p.43). Na LDB, o artigo 26 afirma: "Os currículos do ensino fundamental e médio devem ter uma base nacional comum, a ser complementada, em cada sistema de ensino e estabelecimento escolar, por uma parte diversificada, exigida pelas características regionais e locais da sociedade, da cultura, da economia e da clientela."

2 Para uma análise das propostas de diretrizes curriculares nacionais não confessional do Fonaper, ver Fonaper, 1996.

3 Conforme Art. 62 da LDB no 9.394/96, "a formação de docente para atuar na educação básica far-se-á em nível superior, em curso de licenciatura, de graduação plena”.(BRASIL, 1996). sino Religioso - FONAPER. A entidade é uma associação de professores e pesquisadores que, ao longo de duas décadas, vêm construindo um ensino não confessional, ou seja, uma educação pautada no estudo do fenômeno religioso, no respeito à diversidade cultural, dos direitos humanos e da cultura da paz. Tal instituição, no entanto, não conseguiu ainda, por forças políticas, que suas propostas fossem institucionalizadas pelo aparelho estatal. Com a Base Nacional Comum Curricular - BNCC, fruto das prerrogativas da Constituição Federal Brasileira de 1988 e da Lei de Diretrizes e Bases da Educação Nacional, n ${ }^{0}$ 9394/1996, ${ }^{1}$ como trataremos mais adiante, o FONAPER se articula nacionalmente para garantir sua concepção pedagógica de Ensino Religioso ${ }^{2}$.

Percebe-se no meio escolar, que muitas escolas ainda convivem com o paradigma do Ensino Religioso pautado no modelo confessional. Muitos educadores(as) não têm a devida formação na área ${ }^{3}$. Como consequência desta realidade educacional temos a reprodução de uma ou mais tradições religiosas. Romper com este modelo no sistema escolar constitui um grande desafio para os que concebem uma educação emancipadora e autônoma frente ao aparelho ideológico do Estado (ALTHUSSER, 2009). Com a 
4 Existem dez Estados no Brasil que têm curso superior de graduação e pós-graduação em Ciências da Religião. São eles: Centro Universitário Municipal de São José-USJ, Universidade Estadual do Amazonas-UEA, Universidade Comunitária da Região de Chapecó, Universidade do Estado do Pará-UEPA, Universidade do Estado do Rio Grande do Norte-UERN, Universidade Estadual de Montes Claros-UNIMONTES, Universidade Federal da Paraíba-UFPB, Universidade Federal de Juiz de Forá-UFJF, Universidade Regional de Blumenau-FURB e Universidade Federal de Sergipe-UFS.
BNCC, muitos professores(as) acreditam que um novo paradigma pode surgir na perspectiva de um novo modelo curricular, que respeite à diversidade religiosa no sistema escolar.

O desafio de definição de um campo de conhecimento é uma tarefa complexa. O reconhecimento do fenômeno religioso como área de conhecimento das Ciências da Religião, como defende o FONAPER, passa por redefinições epistemológicas e metodológicas para conquistar seu status e credibilidade no meio científico e escolar. Tal esforço vem se desenhando fortemente no meio acadêmico. Cursos de Ciências da Religião com licenciatura em Ensino Religioso (ER), curso de formação docente, curso de especialização e pós-graduação estão formando e qualificando educadores na perspectiva de um novo paradigma para o ER no país ${ }^{4}$.

Nosso objetivo maior é analisar os desafios e as perspectivas do ER como área de conhecimento na BNCC, bem como discutir como esta disciplina pode ser uma ação pedagógica dialógica, reflexiva, crítica e emancipadora?

\section{O ENSINO RELIGIOSO COMO DISCIPLINA NO CURRÍCULO ESCOLAR}

O Ensino Religioso (ER) nos remete a muitas controvérsias e posições políticas e pedagógicas ao longo da história do país. O ER fazia parte da educação no Brasil desde o período colonial. A chegada ao território brasileiro da Companhia de Jesus, em 1549, com o objetivo de catequização dos povos indígenas, marcaria profundamente a presença dos ensinamentos do catolicismo em terras brasileiras. Nesse período, o ER era visto como instrução religiosa e tinha como objetivo a formação moral do indivíduo. Já no período do Brasil imperial, observam-se ideias do respeito à diversidade cultural e de crença do povo brasileiro. Tal evidência, como percebeu Junqueira, aparece na constituição do império (JUNQUEIRA, 2002, p. 6). Com a proclamação da República, em 1889, as ideias dos iluministas e positivistas passam a influenciar fortemente a educação no Brasil. Nessa época, o ER já era alvo de debates políticos, disputas hegemônicas e ideológicas de representantes de grupos religiosos, educadores e políticos.

O referido período estabeleceu a separação entre a Igreja e o Estado. Enquanto no período colonial e imperial assistimos a uma estreita relação entre Estado e Igreja, na República, por outro lado, surgiria o direito da liberdade de culto e o reconhecimento do pluralismo religioso. Mas este deslocamento do Estado é muito relativo, pois ainda se percebe uma forte presença de diferentes tradições religiosas nas decisões de como o Ensino Religioso deve ser concebido nas escolas. Os preceitos legais vigentes hoje não garantem que a disciplina de ER seja ministrada de forma não proselitista, conforme determina a Constituição 
5 A Constituição de 1988 assegura o ER nas escolas públicas quando afirma no seu artigo 210 e parágrafo $1^{0}$ :"O ensino religioso, de matrícula facultativa, constituirá disciplina dos horários normais das escolas públicas de ensino fundamental." O dispositivo legal seria seguido pela Lei de Diretriz e Base da Educação Nacional (LDBEN) no 9394/96 no seu artigo 33, quando reforça o direito do cidadão ao ER nas escolas públicas de ensino fundamental e respeitando à diversidade cultural religiosa e proibindo "quaisquer formas de proselitismo" (Grifos nossos) (LDBEN, 1996). O proselitismo religioso é a perpetuação de crenças e práticas religiosas, que se colocam como verdades únicas. O proselitismo marcou profundamente o período colonial e imperial, quando a relação do Estado e Igreja eram muito próxima.

6 A Resolução CEB/CNE nº 2/1998 incluiu o Ensino Religioso como uma das áreas de conhecimento. Essa determinação foi ratificada pelas Resoluções CNE/CEB n ${ }^{\circ}$ 4/2010 e $\mathrm{n}^{\mathrm{o}}$ 7/2010, que mantiveram o Ensino Religioso como uma das cinco áreas de conhecimento do Ensino Fundamental de o9 (nove) anos.

7 Exemplos de disciplinas com forte componente ideológico eram: Educação Moral e Cívica, e Organização Social e Política do Brasil. de $1988,{ }^{5}$ visto que se observam, como afirmado anteriormente, concepções doutrinárias e confessionais no sistema escolar. Tal indefinição do ER, como área de conhecimento científico, tem gerado conflitos entre educadores e a comunidade escolar em geral, uma vez que a falta de uma diretriz curricular deixa uma indefinição para o trabalho pedagógico.

Os anos 90 foram marcados por profundas transformações e mobilizações que impactaram no ER como disciplina no sistema escolar do país. Já em 1997, no governo do presidente Fernando Henrique Cardoso (1995-2002), a mencionada lei, no seu art. 33, sofre alterações pela lei $\mathrm{n}^{0}$ 9.475/97. O ER seria agora ministrado por educadores que garantissem o direito do educando à diversidade religiosa e proibido, assim, qualquer forma de proselitismo ${ }^{6}$.

Era o começo da construção de uma nova perspectiva curricular para a disciplina de ER. Conteúdos de religião ou religiões começam a perder espaço para o paradigma do Ensino Religioso como área de conhecimento científico, ou seja, como estudo do fenômeno religioso e o respeito ao pluralismo cultural.

\section{O CURRÍCULO E O ENSINO RELIGIOSO NA BNCC}

Com o processo de redemocratização do país, a partir de 1985, assistimos a uma série de reformas curriculares, disputas epistemológicas e concepções de práticas pedagógicas. Educadores, políticos e intelectuais discutem e formulam novos currículos para superar o modelo ditatorial curricular vigente. Surgem modelos de currículos mais próximos dos currículos científicos e autônomos frente ao aparelho ideológico do Estado ( ALTHUSSER, 2009). As disciplinas ideologizadas, ${ }^{7}$ que davam sustentação ao regime militar, iam aos poucos cedendo lugar a novas disciplinas no meio escolar.

Ileizi Fiorelli Silva, ao tratar dos desafios institucionais e epistemológicos no ensino, destaca que as reformas do Estado, nos campos acadêmico e científico, são frutos de disputas ideológicas e conflitos no seio das classes dirigentes. A educação, segundo ela, é contextualizada (elaborada) no meio científico e recontextualizada nos aparelhos do Estado. É o que ela chama de "comunicação pedagógica”, com um "discurso pedagógico". É, desta forma, que os saberes são reorganizados, disseminados no meio escolar (SILVA 2007, p. 405 ).

Neste mesmo sentido, Bernsteim, em seus estudos da educação inglesa, nota que os currículos reproduzem códigos e "habitus" produzidos na academia e centros de pesquisa. Por sua vez, tal conhecimento é recontextualizado no sistema escolar. Em outras palavras, o processo de seleção dos currículos, a classificação, a transmissão e a avaliação refletem a distribuição do poder e o controle sobre os indivíduos. (BERNSTEIM, 1997 ) 
8 Entre os autores que contribuíram para este novo paradigma na sociologia da educação destacamos Bourdieu e Passeron,1977.
Silva, quando discute currículo no sistema de ensino, identifica quatro "modelos" de currículos, que se alternam ou se sucedem nas políticas de reforma educacionais no país. São eles: currículo clássico-científico, currículo tecnicista (regionalizado), currículo das competências (regionalizado) e currículo científico (SILVA, 2007, p. 409). No primeiro modelo, o currículo clássico-científico, as escolas de ensino médio estavam centradas na política de formação das elites. Os alunos eram preparados para ocupar as vagas em curso de maior prestígio social. Já para os estudantes, oriundos da classe trabalhadora, a educação era voltada para a formação de uma força de trabalho profissionalizante. Prevalecia no meio escolar uma didática de memorização. As identidades pedagógicas eram direcionadas para um país moderno. No segundo, o currículo tecnicista (regionalizado), ocorre um esvaziamento científico nas escolas. Os governos militares, pós 1964, excluem disciplinas nas áreas das ciências humanas e introduzem conhecimentos aplicados e técnicos, como o estudo da gramática e não da literatura, fórmulas da física, e não os fundamentos da Física ou da Química, por exemplo. No terceiro, o currículo da competência, está diretamente relacionado à reorganização do trabalho, na era da produção flexível, do trabalhador polivalente na indústria poupadora de força de trabalho e da acumulação de capital. Era o período do empobrecimento dos conteúdos e da ciência. Por último, o currículo científico. O processo de redemocratização do país alavancou uma série de reformas curriculares pelos estados. Entram em cena teorias pedagógicas e disputas para superar o modelo curricular autoritário e esvaziado de conteúdos e de significados. Surge, assim, o currículo científico, em que resgata as disciplinas de Ciências Humanas e Sociais, o papel do professor intelectual e a escola como instituição privilegiada e transmissora de cultura (SILVA, 2007, p. 414).

Foi a partir dos anos 60 que surgiu uma das mais importantes teorias no campo da educação, o problema das desigualdades escolares ${ }^{8}$. Até então, o pensamento nas Ciências Humanas era fortemente marcado pela predominância das ideias funcionalista e positivista. A escola era entendida como instituição que integraria o indivíduo ao meio social e garantiria a superação do atraso social e econômico. Uma nova sociedade poderia emergir mediante acesso público ao meio educacional. Os indivíduos competiriam no sistema de ensino com as mesmas oportunidades. Esta sociedade seria mais justa, igualitária, meritocrática e moderna, pois permitiria a igualdade de oportunidades para todos. A escola asseguraria, deste modo, a inclusão social de todos os jovens e difundiria o conhecimento científico.

O grande corte epistemológico, que se dá a partir dos anos 6o, foi justamente o de revelar que a origem social tem um peso determinante no destino escolar do estudante e na profissão que irá desempenhar na vida adulta. A escola não era mais entendida como espaço democrático, de 
9 Destacamos Apple (1984), Giroux,( 1997), entre outros. igualdade de oportunidades, justiça social e transformadora da realidade social, mas o lugar de reprodução das desigualdades sociais. A origem social dos alunos, sua classe, etnia, sexo, onde morava, entre outros, eram imperativos para determinar o desempenho escolar e o lugar que iria ocupar na estrutura social.

Historicamente, as instituições de ensino têm se omitido em seu papel de educar os docentes como intelectuais. Giroux acredita que isso acontece devido à absorção da racionalidade tecnocrática, que separa teoria e prática, ignorando ações pedagógicas reflexivas e criativas do professor. O docente tem pouca autonomia no seu trabalho. As escolas de formação, de acordo com ele, estão preocupadas em instrumentalizar os educadores para o domínio de técnicas pedagógicas, anulando, assim, a criatividade e a crítica. Em outras palavras, um mero reprodutor de tarefas, de aplicação de conteúdos e, portanto, acrítico e apolítico. (GIROUX, 1997, p. 23).

Esse modelo de formação profissional é parte constitutiva da racionalidade técnica, que privilegia o saber teórico em detrimento do saber prático. Tal modelo tecnicista de educação foi refutado também por Giroux, que o considera como "ideologias instrumentais", as quais limitam a capacidade criadora do professor e reduzem o educador a simples executor de tarefas burocráticas e cumpridor de programas curriculares. (GIROUX, 1992, p. 12).

A racionalidade técnica busca criar uma ideologia no corpo docente para impedir a participação crítica da produção de projetos políticos e curriculares. Apple verificou uma tendência crescente da perda da autonomia dos professores no desenvolvimento e planejamento dos currículos. Surge uma produção de "pacotes curriculares", isto é, o professor é orientado a proceder determinadas tarefas escolares e transmitir os conteúdos já previamente classificados. (APPLE, 1996, p. 54 ).

Apesar disso, encontramos concepções emancipatórias da escola nas reflexões de diferentes autores da sociologia da educação. ${ }^{9}$ Sabemos que tal perspectiva já aparecia em Marx. A educação, para Marx, era entendida tanto como um instrumento de inculcação ideológica da classe dominante, quanto um importante instrumento revolucionário, visto que poderia servir de alavanca para a emancipação e mudança social, pois o mesmo conhecimento produzido para o avanço tecnológico, por exemplo, que fragmentou o trabalho fabril, poderia ser utilizado para romper com a alienação do trabalho. A teoria crítica reconhece também a escolarização promovida pelo Estado como parte do aparelho ideológico, da estrutura classista, que contribui para a hegemonia burguesa.

O Ensino Religioso (ER), como disciplina no currículo escolar, passou nas últimas três décadas, por processos de ressignificação e reestruturação pedagógica. Uma complexa rede de relações políticas e interesses de grupos configurou o campo do ER no sistema de ensino. Essa 
10 O Ensino Religioso aparece na primeira e segunda versão da BNCC, no entanto, ela foi retirada pelo Ministério da Educação na terceira versão. O Conselho Nacional de Educação - CNE debateu pelo país a BNCC. O Fonaper participou dos debates e pressionou os integrantes do CNE a rever a proposta encaminha pelo Ministério da Educação. $O$ resultado da luta do FONAPER foi a volta do Ensino Religioso na BNCC em 2017.

11 A Ação foi movida pela Procuradoria Geral da República (PGR), que propunha o ER não confessional. O STF acabou decidindo, em uma votação bastante apertada, pela confessionalidade do ER. Assim, a Corte Suprema, em 2018, no Acórdão de Ação Direta de Inconstitucionalidade - ADI 4439/DF, decide: "Ação direta julgada improcedente, declarando-se a constitucionalidade dos artigos 33, caput. § $1^{\circ}$ e $2^{0}$, da Lei 9394/1996, e do Art.11 $\S 1^{\circ}$, do acordo entre o Governo da República Federativa do Brasil e afirmando-se a constitucionalidade do Ensino Religioso Confessional como disciplina facultativa nos horários normais das escolas públicas de ensino fundamental".(STF de ADI 4439/ DF). http://www.stf.jus.br/arquivo/cms/ noticia Noticia STF /anexo/ADI4439AM. pdf , em junho 2018. configuração de forças, todavia, ainda convive no seio do aparelho estatal, com disputas pela hegemonia de suas crenças e conquistas de legitimidade e poder.

O modelo de ER, na perspectiva das Ciências da Religião, defendida pela Fonaper, ou seja, o conhecimento religioso como patrimônio da humanidade, que deve expressar conteúdos e diálogos com diferentes matrizes religiosas e não religiosas, é uma ruptura radical com o modelo de catequização, que defende o ER de base cristã, de reflexão acrítica, apolítica e monocultural. A concepção teológica também se apoia nos princípios do cristianismo, com diferentes matrizes religiosas, mas é um modelo teológico de consenso, ou seja, está voltada em difundir a moralidade, a ética cristã e a cidadania.

O modelo de ER defendido pelos fonaperianos, ou seja, o estudo do fenômeno religioso, constitui uma ruptura epistemológica e pedagógica. Tal ruptura ganhou força com a inclusão do ER na $\mathrm{BNCC}^{10}$. Mas as tensões no ambiente escolar sobre qual currículo prevalecerá no ER, ou seja, confessional ou não confessional, chegou até a Suprema Corte ${ }^{11}$. Em 2017, o Supremo Tribunal Federal (STF) decidiu pela confessionalidade na escola, o que acirrou as incertezas de qual modelo curricular será seguindo nas escolas no país.

Mudanças curriculares são decorrentes da hegemonia política de grupos sociais dominantes presentes no seio do aparelho do Estado. A BNCC deve ser entendida no contexto da crise do modelo de acumulação de capital e da reprodução de uma cultura dominante e colonial. O capital precisa se reproduzir e a escola, como parte do aparelho do Estado, qualificará a força de trabalho necessária para que ele (o capital) se reproduza. Portanto, a escola não apenas repassa conhecimento, mas garante que ele, o capital, mantenha seu ciclo de reprodução e dominação societal. Em outras palavras, o sistema educacional é parte do aparelho ideológica de grupos hegemônicos. É a escola que reproduz a força de trabalho e as relações de produção na sociedade. $O$ sistema escolar não ensina apenas a ler, a escrever, a somar e a dividir, o indivíduo também aprende habilidades, regras de bom comportamento e submissão.

A BNCC surge na política educacional como algo neutro, necessário, inevitável, uma vez que ela atenderia aos interesses de todos os segmentos sociais. Ela, na verdade, esconde as contradições sociais e os problemas inerentes à sociedade capitalista. O sistema escolar não está acima de grupos sociais dominantes, pois ele foi e continua sendo produtor e reprodutor de cultura e desigualdades em diferentes períodos da história.

O currículo é produto de antagonismos de grupos sociais, disputas de valores e saberes. A BNCC não é, por conseguinte, neutra. Ele, o currículo, é resultado de um processo de seleção de indivíduos ou grupos sociais, que determinam qual conhecimento é "legítimo", isto é, o que pode ou não ser ensinado na escola. 
12 Tal concepção pode representar o enfraquecimento de grupos religiosos, que defendem o ER confessional, bem como o declínio de concepções de intelectuais que defendem o fim da disciplina no sistema educacional no país. Entre os intelectuais que defendem o fim do ER nas escolas destacamos Luiz Antônio Cunha. Em seu artigo intitulado "A entronização do ensino religioso na BNCC", no artigo, Cunha critica a FONAPER e seus diretores. Ver Cunha, 2016.
Mas o currículo não é apenas produto de conflitos de grupos sociais e disputas de valores e saberes. Ele pode ser, também, a expressão de uma força contrária ao movimento do capital. A escola, por exemplo, pode viver, como já observou Apple, momentos de conflitos ideológicos contraditórios ao contribuir para o processo de acumulação de capital, reprodução da força de trabalho, desigualdades sociais e, ao mesmo tempo, formar estudantes críticos para enfrentar a força do capital e construir uma sociedade mais democrática e indivíduos emancipados. (APPLE, 1996)

Deste modo, percebe-se que a BNCC pode ser, também, um movimento contraditório que pode criar, recriar, destruir ou construir modelos e formas de expressão social, política e cultural. O Ensino Religioso aparece na BNCC como um currículo de base científica e parte constitutiva das ciências humanas, ou seja, um currículo fundado no paradigma das Ciências da Religião onde o fenômeno religioso é seu objeto de análise. ${ }^{12}$

As transformações do capitalismo globalizado colocam novos desafios teóricos e metodológicos para o Ensino Religioso (ER). A sociedade exige novas reflexões, conceitos e interpretações, o que possibilita novas configurações, horizontes e potencialidades para a disciplina se consolidar no meio escolar.

É preciso pensar o ER como objeto de análise crítica do fenômeno religioso, ou melhor, com suas contradições, interesses, antagonismos e conflitos ideológicos. Ele deve romper com a visão colonialista, monocultural e acrítica. Também precisa estar fundamentada na desnaturalização do fenômeno social, quer dizer, não cair nas armadilhas de explicações vagas e superficiais, que perdem de vista a historicidade e a criticidade. Com a BNCC, o Ensino Religioso tem, assim, o compromisso de desmistificar conceitos naturalizantes, que foram instituídos ao longo da história por interesses políticos e de grupos religiosos.

Diante disso, o(a) professor(a) do ER tem o desafio de contribuir com a formação de estudantes críticos e reflexivos, preparando-os para o exercício de uma sociedade mais democrática. Ou seja, é preciso uma pedagogia emancipadora, comprometida em desconstruir velhos significados e práticas colonialistas. Diante disso, é necessário começar a incluir práticas pedagógicas de alteridade, de ética e de dignidade humana. $\mathrm{O}$ educador tem o desafio de erradicar relações de poder, dominação e de práticas de homogeneização cultural. Um profissional habilitado em ER tem a competência para instigar o seu aluno a pensar criticamente a sociedade e o mundo em que vive, com suas contradições, os seus antagonismos e os interesses de classe. Sabemos que para atingir tais objetivos de formação integral, de ética da alteridade e no diálogo religioso e não religioso, que são os princípios básicos para trabalhar a diversidade cultural e, assim, poder enfrentar os problemas de discriminação, de violência, do etnocentrismo e do preconceito de grupos hegemônicos, o educador precisa 
fazer uma opção política pedagógica ou reproduzir as velhas práticas de dominação e reprodução social.

Para que tal prática pedagógica emancipadora ocorra no ER não basta, certamente, apenas conteúdos críticos, reflexivos e de perspectiva que respeite a ética e a diversidade cultural e religiosa. Devemos considerar antes o(a) professor(a) como intelectual transformador, como defende Giroux, ou seja, um ator cujo papel da docência é contribuir para a construção de uma sociedade mais justa e indivíduos emancipados ( GIROUX, 1997). Isso significa dizer que cabe a este professor(a) lutar contra práticas pedagógicas tecnicistas e reprodutoras de desigualdade social.

\section{CONSIDERAÇÕES FINAIS}

A incorporação do Ensino Religioso (ER) na BNCC não significa o fim de uma cultura de dominação e/ou reprodução monocultural, pois a escola, como procuramos mostrar, é parte constitutiva do aparelho ideológico do Estado. As relações de dominação religiosa e lutas por hegemonia continuam a serem reproduzidos na sociedade e sendo perpetuadas pelo sistema escolar vigente.

Os intelectuais críticos, que estudam o fenômeno religioso na sua mais diversa complexidade, tem como desafio a formação de professores comprometidos com esta nova proposta de diretriz curricular nacional, pois os professores(as) formados(as) em Ciências da Religião, com licenciatura em Ensino Religioso, ainda são em pequeno número no país, pois há poucos cursos de licenciatura, que fornecem esta formação específica. Caberá ao poder público oferecer cursos de capacitação continuada para tentar amenizar e combater o grande déficit existente nesta área.

Outro grande desafio para o Ensino Religioso é a falta de material didático. Este recurso pedagógico é ainda bastante limitado e, quando existe, seu conteúdo é reprodutor de determinada matriz religiosa ou determinada etnia, gênero e sexualidade. As instituições de ensino superior terão que desenvolver ações de incentivo na produção dos referidos materiais. O desafio é grande, uma vez que as universidades ainda convivem com uma tradição bacharelesca, ou seja, muito mais focada na pesquisa do que na formação de professores com a produção de suporte pedagógico aos licenciados.

Apesar dos grandes desafios que são colocados para o ER, a BNCC pode ser o começo de uma renovação epistemológica e metodológica para tal disciplina, isto é, uma educação pautada, como vem propondo o FONAPER ao longo dos seus mais de 20 anos, nos fundamentos do pensamento científico. Para que isso se torne realidade, é preciso que o ER se articule com outras disciplinas e o(a) professor(a) se torne um instrumento de perpetuação de uma pedagógica emancipadora. Ou seja, uma pedagogia para a formação de um ser humano critico, reflexivo e sujeito de sua história. 


\section{REFERÊNCIA}

ALTHUSSER, Louis. Aparelhos ideológicos do Estado. $10^{\mathrm{a}}$ edição, Paz e Terra, 2009.

APPLE, Michael. Ideologia e currículo. São Paulo: Brasiliense, 1992

1996.

Educação e Poder. São Paulo: ARTMED,

BRASIL. Lei de Diretrizes e Bases da Educação Nacional no 9.394 de 20 de dezembro de 1996. Brasília:Diário oficial da União, 1996.

BERNSTEIN, basil. A propos Du curriculum. In: Forquin, J.C (org). Les sociologues de l'education américain et britanniques; présentation et choix de textes. Paris, Bruxelles: De Boeck Université/INRP, 1997.

BASE NACIONAL COMUM CURRICULAR. Ministério da Educação. $2^{\mathrm{a}}$ versão preliminar. Brasília. 2016.

BOURDIEU, Pierre and PASSERON, Jean-Claud.C. Reproductin, Beverly Hills: Sage, 1977.

FONAPER. Proposta de diretrizes Curriculares Nacionais, para o Ensino Religioso, 1996.

CUNHA, Luiz Antônio. A entronização do ensino religioso na BNCC. Revista Eletrônica, campinas, v.37, $\mathrm{n}^{\mathrm{0}} 134,2016$.

GIROUX, Henry. Os professores como intelectuais. Rumo a uma pedagogia crítica da aprendizagem. Porto alegre: Artmed, 1997.

GIROUX, Henry. Colégio, Crítica e Política Cultural, $3^{\text {a }}$ edição, São Paulo: Cortez, 1992.

JUNQUEIRA, Sergio Rogério Azevedo. O processo de escolarização do Ensino Religioso no Brasil. Petrópolis: Vozes, 2002.

SILVA, Ileizi Fiorelli. A sociologia no ensino médio: os desafios institucionais e epistemológicos para a consolidação da disciplina. Rio Grande do Norte: Cronos, 2007. 